\title{
Applications of the Sub Equation Method for the High Dimensional Nonlinear
}

\author{
Evolution Equation \\ Serbay DURAN ${ }^{1 *}$, Doğan KAYA ${ }^{2}$ \\ ${ }^{1}$ Adiyaman University, Faculty of Education, Department of Mathematics, Adiyaman, Turkey \\ ${ }^{2}$ Department of Mathematics, Istanbul Commerce University, Uskudar, Istanbul, Turkey \\ Geliş / Received: 16/02/2021, Kabul / Accepted: 03/11/2021
}

\begin{abstract}
In this article, the Generalized (3+1)-dimensional Shallow Water-Like (SWL) equation is taken into consideration and exact solutions have been constructed of the SWL equation using sub equation method. This method is an easier and efficient method for finding analytic solutions of the nonlinear evolution differential equation. The method appears to be easier and faster for symbolic computation. Moreover, 2D, 3D and contour graphical representation of the obtained results of the specified equation is made using a ready-made package program for certain values and thus the conformity of the founded results has been demonstrated.

Keywords: Sub equation method, the Generalized (3+1)-dimensional Shallow Water-Like equation, Exact solution, Traveling wave solution.

\section{Yüksek Boyutlu Doğrusal Olmayan Evrim Denklemi için Alt Denklem Metodunun Uygulanması}

$\ddot{O} \mathbf{z}$

Bu makalede Genelleştirilmiş $(3+1)$ boyutlu sığ su benzeri (SWL) denklemi dikkate alınmış ve SWL denkleminin alt denklem yöntemi kullanılarak kesin çözümleri oluşturulmuştur. Bu metot, doğrusal olmayan evrim denklemlerinin analitik çözümlerini bulmak için daha kolay ve verimli bir yöntemdir. Metot, sembolik hesaplama için daha kolay ve daha hızlı görünmektedir. Ayrıca, belirtilen denklemin elde edilen sonuçlarının 2 boyutlu, 3 boyutlu ve kontur grafiksel gösterimi belirli değerler için hazır paket programı kullanılarak yapılmış ve böylece bulunan sonuçların uygunluğu gösterilmiş̧ir.
\end{abstract}

Anahtar Kelimeler: Alt denklem metodu, Genelleştirilmiş (3+1) boyutlu sığ su benzeri denklemi, Tam çözüm, Yürüyen dalga çözümü.

\section{Introduction}

The models of many physical phenomena that occur in the world appear in applied mathematics as nonlinear evolution differential equations (NLEEs). Therefore, these NLEEs analytical and numerical solutions are very important in fields such as fluid dynamics (Benetazzo et al., 2021), virus spread (Gao et al., 2020), biology (Yavuz and Yokus, 2020), and so on (Duran, 2020; Yokus and Yavuz, 2020; Eckart, 1948; Sulaiman, et al., 2018; Fellman, 2007; Akturk, 2020; Duran et al., 2017; Yokus et al. 2019; Kaya et al. 2020; Yokus et al., 2021). In particularly, the soliton obtained as a result of these NLEEs and their applications were first defined by Scott 
Russell (1845). Later, it was developed with advanced studies on the concept of soliton by Scott et al., (1973). To reach these solutions, many analytical methods have been developed for the solutions of NLEEs. Some of these methods: exponential function method (Bulut et al., 2016), Bernoulli sub equation method (Durur et al., 2020; Baskonus and Bulut, 2015), modified exponential function method (Silambarasan and Kilicman, 2021), the sine-Gordon expansion method (Ali et al., 2020), (1/G')-expansion method (Yokus et al., 2020), $\left(G^{\prime} / G, 1 / G\right)$ expansion method (Duran, 2020; Duran 2021) and so on (Durur, 2020; Durur et al., 2020; Duran, 2021; Tabassum, 2021).

$(3+1)$-dimensional Shallow Water-Like (SWL) equation (Dusunceli, 2019) is a nonlinear evolution equation that has become quite popular recently

$$
u_{x x x y}+3 u_{x x} u_{y}+3 u_{x} u_{x y}-u_{y t}-u_{x z}=0
$$

When we examine the literature, the SWL equation has been examined by many researchers with the help of different methods. We can define the hierarchical order of some of the important ones as follows: Traveling wave solutions were created by Tran and Gao (1996) with the help of the generalized tanh algorithm method. Traveling wave solutions have been reached by Zayed (2010) with the help of $\left(G^{\prime} / G\right)$-expansion method. These solutions were classified as hyperbolic, trigonometric and rational functions. By giving special values to the parameters obtained here, solitary waves were created from traveling waves. Grammian and Pfaffian solutions were obtained for the SWL equation by Tang et al. (2012). Rational and lump solutions for Eq. (1) with the help of a generalized bilinear operator were presented by Zhang et al. (2017). The exact solutions of Eq. (1) were obtained with the help of the Bernoulli subequation method by Dusunceli (2019).

The aim of this study is to obtain traveling wave solutions with the help of sub equation method (Durur et al., 2020) for the SWL equation, which is very rich in literature. In these traveling wave solutions, we have obtained, graphs are presented with the help of special values given to parameters.

\section{Sub-Equation Method}

Let us explain the methodology of the sub equation method to solve NLEEs. Consider the NLEEs as

$$
T\left(u, \frac{\partial u}{\partial t}, \frac{\partial u}{\partial x}, \frac{\partial u}{\partial y}, \frac{\partial u}{\partial z}, \frac{\partial^{2} u}{\partial x^{2}}, \ldots\right)=0
$$

\section{Applying the wave transformation}

$$
\begin{gathered}
\boldsymbol{u}(\boldsymbol{x}, \boldsymbol{y}, \boldsymbol{z}, \boldsymbol{t})=\boldsymbol{U}(\xi)=\boldsymbol{U}, \\
\xi=x+k y+m z-w t,
\end{gathered}
$$

where $w, k$ are constants and $w$ is the velocity of the wave. We may be converted into the following nonlinear ordinary differential equation for $U(\xi)$ : 


$$
\mathrm{L}\left(U, U^{\prime}, U^{\prime \prime}, U^{\prime \prime \prime}, \ldots\right)=0
$$

The solution of Eq. (3) is assumed to have the form

$$
U(\xi)=\sum_{i=0}^{n} a_{i}(G(\xi))^{i}, a_{\mathrm{n}} \neq 0
$$

where $a_{i},(0 \leq i \leq n)$ are constants. These $a_{i}$ values will then be found with the help of the balancing term. The positive integer $n$ defined in Eq. (4) is the balance term and is found with the help of two factors. These factors are taken into consideration the property of balancing and the solution of the Riccati equation.

$$
G^{\prime}(\xi)=(G(\xi))^{2}+\mu,
$$

where $\mu$ is an arbitrary constant. The Riccati equation in Eq. (5) gives certain exclusive solutions as follows.

$$
G(\xi)=\left\{\begin{array}{c}
-\sqrt{-\mu} \tanh (\sqrt{-\mu} \xi), \mu<0 \\
-\sqrt{-\mu} \operatorname{coth}(\sqrt{-\mu} \xi), \mu<0 \\
\sqrt{\mu} \tan (\sqrt{\mu} \xi), \mu>0 \\
-\sqrt{\mu} \cot (\sqrt{\mu} \xi), \mu>0 \\
\left.-\frac{1}{\xi+R}, \mu=0 \text { (R is const. }\right)
\end{array}\right.
$$

In Eq. (3) if we apply the Eq. (5) and Eq. (4), with respect to $G(\xi)$, a nonlinear algebraic equation system, we reached the new polynomial. All the coefficients $G(\xi)^{i},(i=0,1, \ldots, n)$ of the obtained polynomial to find constants $a_{i}$ are set to zero. In the nonlinear algebraic equation system, we have obtained as described above, constants are determined as $\mu, \tau, R$, $a_{i}, \quad(i=0,1, \ldots, n)$. Solving this system with the help of a ready-made package program and substituting the constants in the relevant equations with the help of Eq. (6), we obtain an exact solution for Eq. (2).

\section{Solutions of the Generalized}

\section{(3+1)-Dimensional SWL Equation}

We consider Eq. (1) and using transformation

$$
\begin{gathered}
\boldsymbol{u}(\boldsymbol{x}, \boldsymbol{y}, \boldsymbol{z}, \boldsymbol{t})=\boldsymbol{U}(\xi)=\boldsymbol{U}, \\
\xi=x+k y+m z-w t, \\
\mathrm{k} U^{4}+6 k U^{\prime} U^{\prime \prime}+(k w-m) U^{\prime \prime}=0 .
\end{gathered}
$$

If the Eq. (7) is integrated according to $\xi$, we can write the following equation

$$
k U^{\prime \prime \prime}+3 k\left(U^{\prime}\right)^{2}+(k w-m) U^{\prime}=0
$$


According to the homogeneous balancing principle, the equilibrium term of Eq. (8) is $n=2$. By using this balancing term in Eq. (4), the following situation is obtained:

$$
U(\xi)=a_{0}+a_{1}(G(\xi))+a_{2}(G(\xi))^{2}
$$

where $a_{1} \neq 0$ or $a_{2} \neq 0$. Eq. (9) is substituted in Eq. (8). Then, by using the polynomial equation, the coefficients are equalled to zero. After doing the necessary operations, the following algebraic equation system is obtained:

$$
\begin{gathered}
(G(\xi))^{0}:-m \mu a_{1}+k w \mu a_{1}+2 k \mu^{2} a_{1}+3 k \mu^{2} a_{1}^{2}=0 \\
(G(\xi))^{1}:-2 m \mu a_{2}+2 k w \mu a_{2}+16 k \mu^{2} a_{2}+12 k \mu^{2} a_{1} a_{2}=0 \\
(G(\xi))^{2}:-m a_{1}+k w a_{1}+8 k \mu a_{1}+6 k \mu a_{1}^{2}+12 k \mu^{2} a_{2}^{2}=0 \\
(G(\xi))^{3}:-2 m a_{2}+2 k w a_{2}+40 k \mu a_{2}+24 k \mu a_{1} a_{2}=0 \\
(G(\xi))^{4}: 6 k a_{1}+3 k a_{1}^{2}+24 k \mu a_{2}^{2}=0 \\
(G(\xi))^{5}: 24 k a_{2}+12 k a_{1} a_{2}=0 \\
(G(\xi))^{6}: 12 k a_{2}^{2}=0
\end{gathered}
$$

Constants $a_{1}, a_{2}, k, \mu, w, m$ are attained from Eq. (10) system with the aid of package program.

\section{Case1.}

$$
a_{1}=-2, a_{2}=0, w=\frac{m+4 k \mu}{k} .
$$

Substituting these obtained values into Eq. (9), the hyperbolic wave solution for Eq. (1) is obtained

$$
u_{1}(x, y, z, t)=a_{0}+2 \sqrt{-\mu} \operatorname{Tanh}\left[\sqrt{-\mu}\left(x+k y+m z-\frac{t(m+4 k \mu)}{k}\right)\right] .
$$
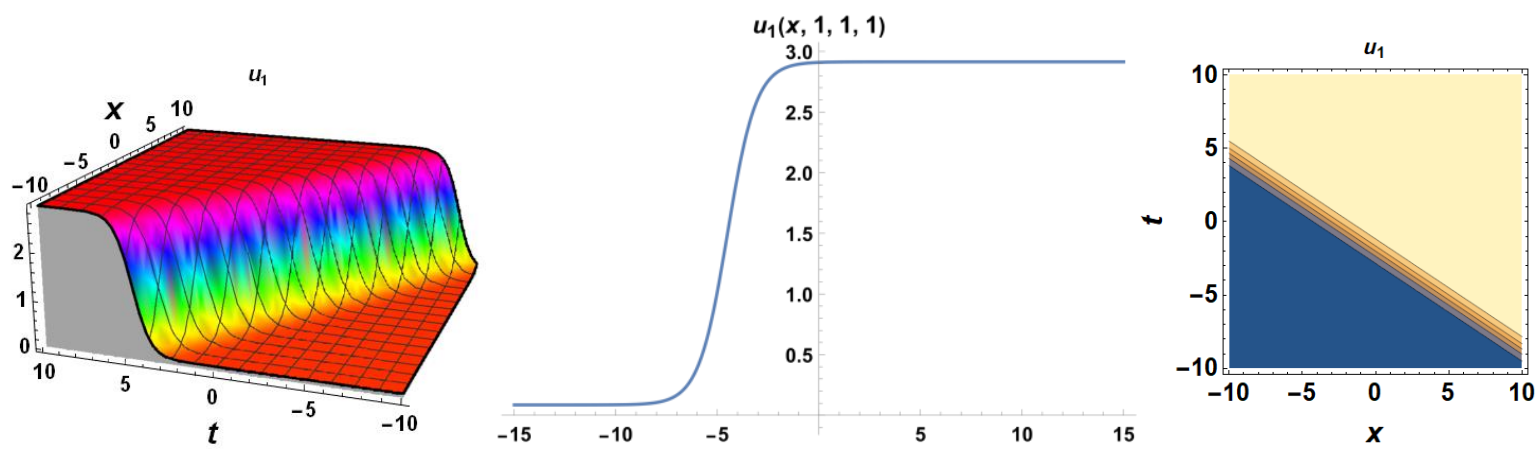

Figure 1. 3D, 2D and contour graphs of $u_{1}(x, y, z, t)$ respectively for $\mu=-0.5, a_{0}=1.5$, $m=1, k=2, y=1, z=1$. 


\section{Case2.}

$$
a_{1}=-2, a_{2}=0, w=\frac{m+4 k \mu}{k} .
$$

Substituting these obtained values into Eq. (9), the hyperbolic wave solution for Eq. (1) is obtained

$$
u_{2}(x, y, z, t)=2 \sqrt{-\mu} \operatorname{Coth}\left[\sqrt{-\mu}\left(x+k y+m z-\frac{t(m+4 k \mu)}{k}\right)\right]+a_{0} .
$$
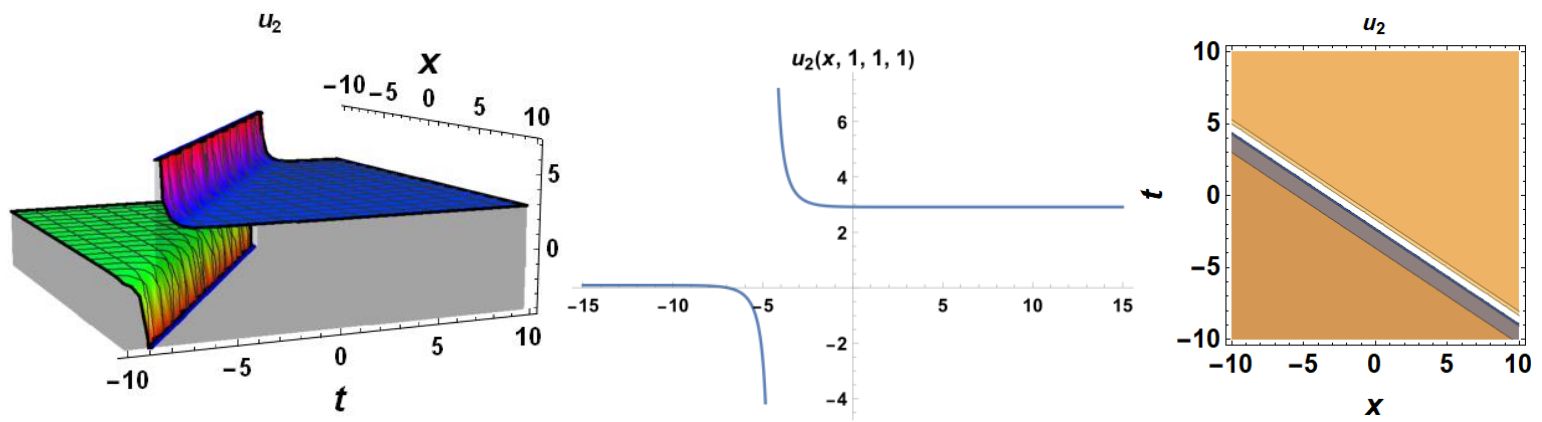

Figure 2. 3D, 2D and contour graphs of $u_{2}(x, y, z, t)$ respectively for $\mu=-0.5, a_{0}=1.5$,

$$
m=1, k=2, y=1, z=1 \text {. }
$$

\section{Case3.}

$$
a_{1}=-2, a_{2}=0, w=\frac{m+4 k \mu}{k}
$$

Substituting these obtained values into Eq. (9), the trigonometric wave solution for Eq. (1) is obtained

$$
u_{3}(x, y, z, t)=a_{0}-2 \sqrt{\mu} \operatorname{Tan}\left[\sqrt{\mu}\left(x+k y+m z-\frac{t(m+4 k \mu)}{k}\right)\right]
$$

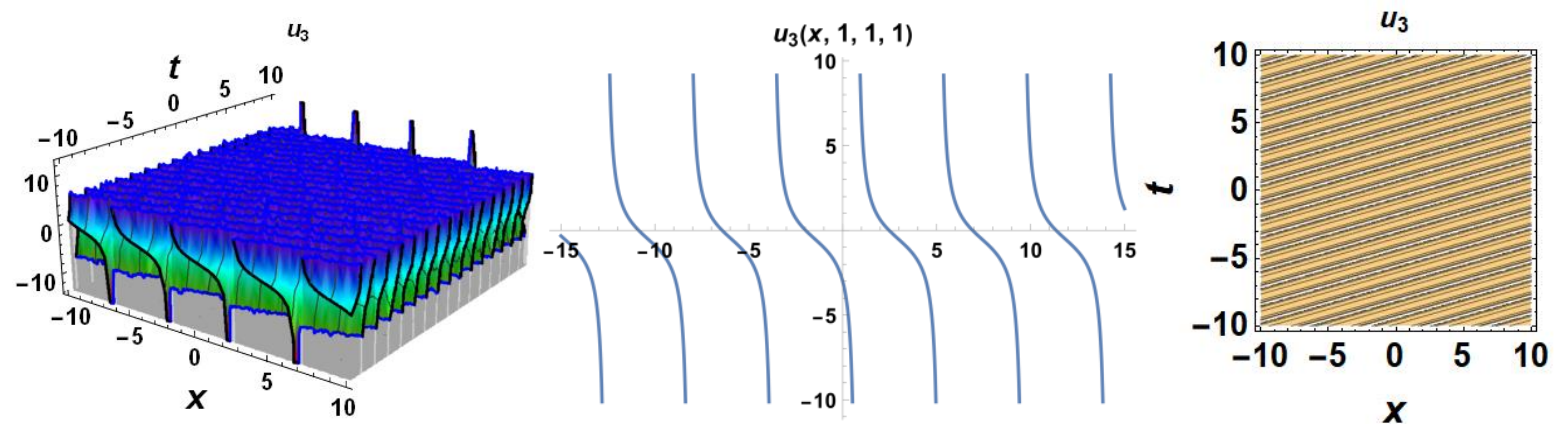

Figure 3. 3D, 2D and contour graphs of $u_{3}(x, y, z, t)$ respectively for $\mu=0.5, a_{0}=-0.5$,

$$
m=3, k=2, y=1, z=1 \text {. }
$$




\section{Case4.}

$$
a_{1}=-2, a_{2}=0, w=\frac{m+4 k \mu}{k} .
$$

Substituting these obtained values into Eq. (9), the trigonometric wave solution for Eq. (1) is obtained

$$
u_{4}(x, y, z, t)=2 \sqrt{\mu} \operatorname{Cot}\left[\sqrt{\mu}\left(x+k y+m z-\frac{t(m+4 k \mu)}{k}\right)\right]+a_{0} .
$$
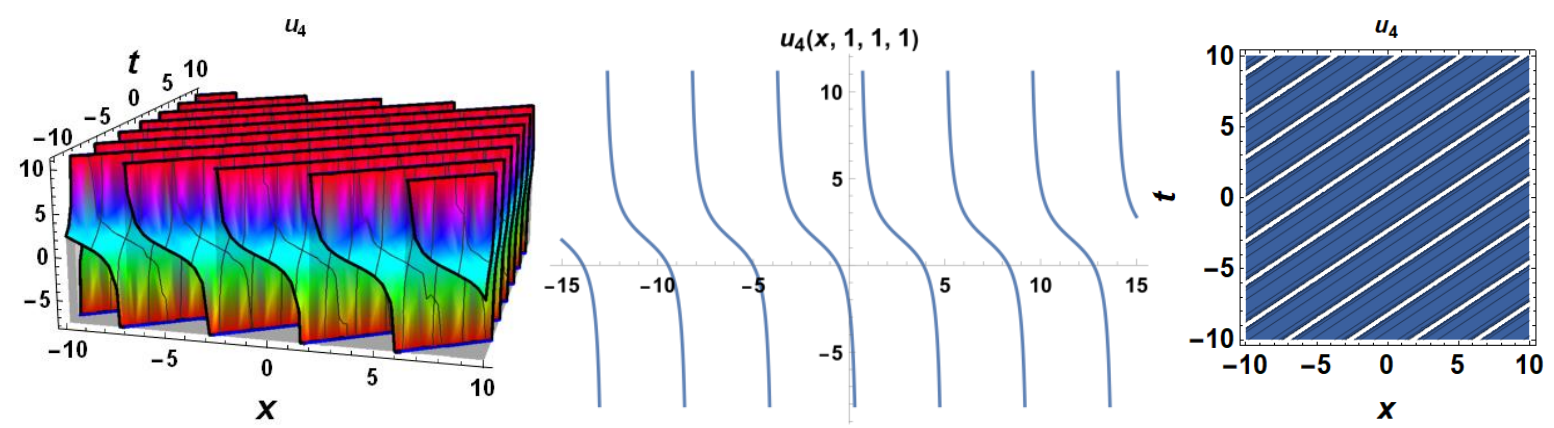

Figure 4. 3D, 2D and contour graphs of $u_{4}(x, y, z, t)$ respectively for $\mu=0.5, a_{0}=1.5$,

$$
m=-1, k=2, y=1, z=1 \text {. }
$$

\section{Case5.}

$$
a_{1}=-2, a_{2}=0, w=\frac{m+4 k \mu}{k}
$$

Substituting these obtained values into Eq. (9), the rational wave solution for Eq. (1) is obtained

$$
u_{5}(x, y, z, t)=\frac{2}{R-\frac{m t}{k}+x+k y+m z}+a_{0}
$$
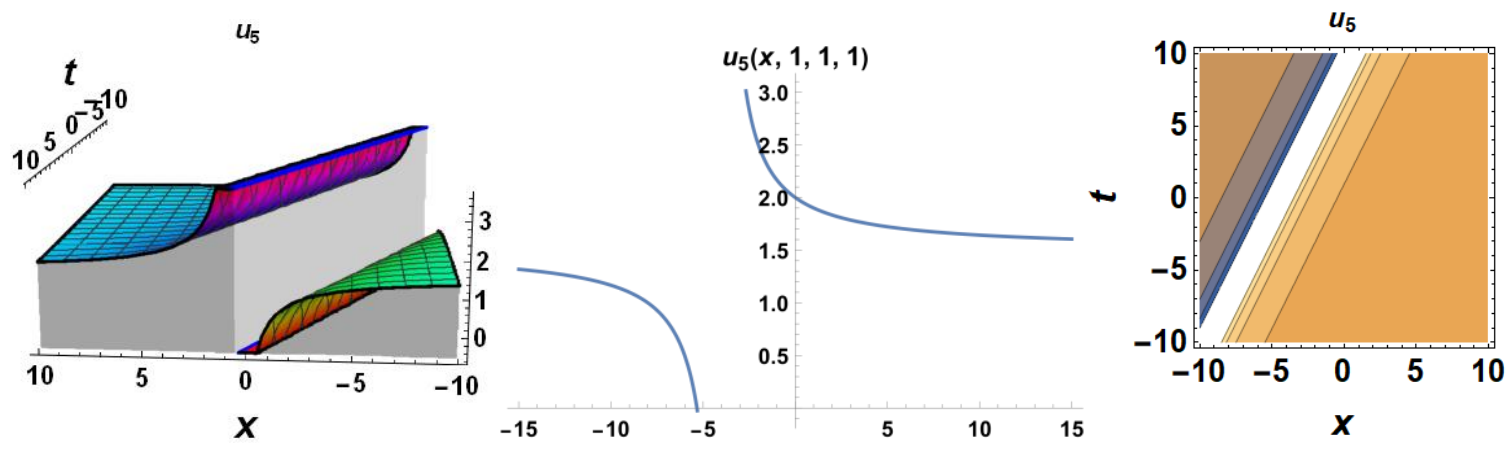

Figure 5. 3D, 2D and contour graphs of $u_{5}(x, y, z, t)$ respectively for $\mu=0, R=1.5$,

$$
a_{0}=1.5, m=1, k=2, y=1, z=1 \text {. }
$$

\section{Conclusion}

In this study, we have obtained the traveling wave solutions of the $(3+1)$ dimensional SWL equation. When these traveling wave solutions were examined, they were classified in hyperbolic, trigonometric and rational forms. The sub equation method applied here is an 
effective method because it produces solutions from all different classes. Therefore, this method, which is easier to apply than other methods, is a very efficient and reliable method to find solutions to NLEEs. Besides, the solutions for the five different situations obtained are graphically shown as 3D, 2D and contour with the help of a ready-made package program.

\section{References}

Benetazzo, A., Barbariol, F., Pezzutto, P., Staneva, J., Behrens, A., Davison, S., \& Cavaleri, L. (2021). "Towards a unified framework for extreme sea waves from spectral models: Rationale and applications", Ocean Engineering, 219, 108263.

Gao, W., H. M. Baskonus, and L. Shi. 2020. "New investigation of bats-hosts-reservoir-people coronavirus model and application to 2019-nCoV system", Advances in Difference Equations (1): 1-11.

Yavuz, M., \& Yokus, A. (2020). "Analytical and numerical approaches to nerve impulse model of fractional-order", Numerical Methods for Partial Differential Equations, 36(6), 1348-1368.

Duran, S. (2020). "Exact Solutions for Time-Fractional Ramani and Jimbo Miwa Equations by Direct Algebraic Method." Advanced Science, Engineering and Medicine, 12(7), 982-988.

Yokus, A., \& Yavuz, M. (2020). Novel comparison of numerical and analytical methods for fractional Burger-Fisher equation. Discrete \& Continuous Dynamical Systems-S, doi, 10.

Eckart, C. (1948). "Vortices and streams caused by sound waves", Physical review, 73(1), 68.

Sulaiman, T. A., Aktürk, T., Bulut, H., \& Baskonus, H. M. (2018). "Investigation of various soliton solutions to the Heisenberg ferromagnetic spin chain equation." Journal of Electromagnetic Waves and Applications, 32(9), 1093-1105.

Fellmann, E. A. (2007). “Leonhard Euler”, Springer Science \& Business Media.

Akturk, T. (2020). "Interaction Solutions of Long and Short Waves in a Flexible Environment.” Alexandria Engineering Journal, 59(3), 1705-1716.

Duran, S., Askin, M., \& Sulaiman, T. A. (2017). "New soliton properties to the ill-posed Boussinesq equation arising in nonlinear physical science", An International Journal of Optimization and Control: Theories \& Applications (IJOCTA), 7(3), 240-247.

Yokus, A., Kuzu, B., \& Demiroğlu, U. (2019). "Investigation of solitary wave solutions for the (3+1)-dimensional Zakharov-Kuznetsov equation.” International Journal of Modern Physics B, 33(29), 1950350.

Kaya, D., Yokuş, A., \& Demiroğlu, U. (2020). "Comparison of exact and numerical solutions for the Sharma-Tasso-Olver equation." In Numerical Solutions of Realistic Nonlinear Phenomena 53-65. Springer, Cham. 
Yokus, A., Durur, H., Kaya, D., Ahmad, H., \& Nofal, T. A. (2021). "Numerical Comparison of Caputo and Conformable Derivatives of Time Fractional Burgers-Fisher Equation." Results in Physics, 104247.

Russell, J. S. (1845). "Report on Waves", Made to the Meetings of the British Association in 1842-43.

Scott, A. C., Chu, F. Y. F., \& McLaughlin, D. W. (1973). "The soliton: A new concept in applied science", Proceedings of the IEEE, 61(10), 1443-1483.

Bulut, H., Atas, S. S., \& Baskonus, H. M. (2016). "Some novel exponential function structures to the Cahn-Allen equation", Cogent Physics, 3(1), 1240886.

Baskonus, H. M., \& Bulut, H. (2015). "On the complex structures of Kundu-Eckhaus equation via improved Bernoulli sub-equation function method", Waves in Random and Complex Media, 25(4), 720-728.

Silambarasan, R., \& Kilicman, A. (2021). "Solitons of nonlinear dispersive wave steered from Navier-Bernoulli hypothesis and Love's hypothesis in the cylindrical elastic rod with compressible Murnaghan's materials", arXiv preprint arXiv:2101.05070.

Ali, K. K., Seadawy, A. R., Yokus, A., Yilmazer, R., \& Bulut, H. (2020). "Propagation of dispersive wave solutions for (3+1)-dimensional nonlinear modified Zakharov-Kuznetsov equation in plasma physics", International Journal of Modern Physics B, 34(25), 2050227.

Yokus, A., Durur, H., Ahmad, H., \& Yao, S. W. (2020). "Construction of different types analytic solutions for the Zhiber-Shabat equation", Mathematics, 8(6), 908.

Duran, S. (2020). "Solitary Wave Solutions of the Coupled Konno-Oono Equation by using the Functional Variable Method and the Two Variables ( $\left.\mathrm{G}^{\prime} / \mathrm{G}, 1 / \mathrm{G}\right)$-Expansion Method.” Adiyaman Üniversitesi Fen Bilimleri Dergisi, 10(2), 585-594.

Duran, S. "Extractions of travelling wave solutions of $(2+1)$-dimensional Boiti-LeonPempinelli system via (G'/G,1/G)-Expansion Method." Optical and Quantum Electronics. (in press).

Durur, H. (2020). "Different types analytic solutions of the (1+1)-dimensional resonant nonlinear Schrödinger's equation using $\left(\mathrm{G}^{\prime} / \mathrm{G}\right)$-expansion method", Modern Physics Letters B, 34 (03), 2050036.

Durur, H., and A. Yokus, and D. Kaya. (2020). "Hyperbolic Type Traveling Wave Solutions of Regularized Long Wave Equation”, Bilecik Şeyh Edebali Üniversitesi Fen Bilimleri Dergisi, 7 (2).

Duran, S. (2021). "Breaking theory of solitary waves for the Riemann wave equation in fluid dynamics.” International Journal of Modern Physics B, 2150130. 
Tabassum, M. F., Akram, S., Mahmood-ul-Hassan, S., Karim, R., Naik, P. A., Farman, M., ... \& Ahmad, H. (2021). "Differential gradient evolution plus algorithm for constraint optimization problems: A hybrid approach." An International Journal of Optimization and Control: Theories \& Applications (IJOCTA), 11(2), 158-177.

Dusunceli, F. (2019). "Exact Solutions for Generalized (3+1)-Dimensional Shallow Water-Like (SWL) Equation”, In Conference Proceedings of Science and Technology, 2(1), 55-57.

Tian, B., \& Gao, Y. T. (1996). "Beyond travelling waves: a new algorithm for solving nonlinear evolution equations", Computer Physics Communications, 95(2-3), 139-142.

Zayed, E. M. E. (2010). "Traveling wave solutions for higher dimensional nonlinear evolution equations using the g'/g-expansion method", Journal of Applied Mathematics \& Informatics, 28(1_2), 383-395.

Ya-Ning, T., Wen-Xiu, M., \& Wei, X. (2012). "Grammian and Pfaffian solutions as well as Pfaffianization for a (3+1)-dimensional generalized shallow water equation”, Chinese Physics B, 21(7), 070212.

Zhang, Y., Dong, H., Zhang, X., \& Yang, H. (2017). "Rational solutions and lump solutions to the generalized (3+1)-dimensional shallow water-like equation", Computers \& Mathematics with Applications, 73(2), 246-252.

Durur, H., Kurt, A., \& Tasbozan, O. (2020). "New travelling wave solutions for KdV6 equation using sub equation method", Applied Mathematics and Nonlinear Sciences, 5(1), 455-460. 